\title{
Relationship of Initial Lactate Dehydrogenase (LDH) with initial tumor load and bone marrow remission in childhood Acute Lymphoblastic Leukemia (ALL)
}

\author{
Tawfique $\mathrm{M}^{1}$, Mannana $\mathrm{MA}^{2}$, Haque $\mathrm{MM}^{3}$, Begum $\mathrm{M}^{4}, \mathrm{Kabir}_{\mathrm{SMRZ}}{ }^{5}, \mathrm{Khan}_{\mathrm{ZJ}} \mathrm{J}^{6}$
}

\begin{abstract}
This was a prospective interventional study conducted in the department of pediatric hematology and oncology in BSMMU during the period from January 2004 to June 2005. The objectives of the study were to observe- The effects of initial tumor load on initial LDH and the relation of initial LDH levels with response to remission induction chemotherapy in childhood ALL.

All the children from one to fourteen years with the confirmed diagnosis of ALL, irrespective of their sex, were included in the study. Out of total 40 cases 21 of them were male and 19 female. As much as $60 \%$ of them were from rural areas and $40 \%$ city dwellers. Before starting chemotherapy for induction of remission complete clinical and laboratory assessments were done. Evaluation was also performed on $7^{\text {th }}, 14^{\text {th }}, 21^{\text {st }}$ and $28^{\text {th }}$ days after the starting of treatment. All the assessments were done to see whether the cases were in bone marrow remission or not.

Initial LDH level was found to have direct correlation with initial WBC as well as initial blast cell count. Mean LDH levels differed significantly between the group having initial hyperleukocytosis $(50 \times 10(9) / L)$ and that below 50x10(9)/L. Mean LDH level was also significantly higher in the cases of ALL with IBC $>25 \times 10(9) / L$ than the group with IBC below $25 \times 10(9) / L$.

The cases with very high initial LDH level responded poorly to dexamethasone monotherapy as well as to polychemotherapy in induction of remission in childhood ALL. Level of initial LDH was observed to be a significant indicator of outcome of induction of remission in childhood Acute Lymphoblastic Leukemia.
\end{abstract}

CBMJ 2013 Jan: Vol 02 No 01: P: 03-08

Key words: Acute Lymphoblastic Leukemia (ALL), Tumor load, Bone marrow remission, Lactate Dehydrogenase (LDH).

\section{Introduction}

Risk adapted polychemotherapy for children with Acute Lymphoblastic Leukemia(ALL) is the basis of success stories in modern clinical oncology. Identification of risk factors therefore, is very important ${ }^{1}$. The ability to identify, at diagnosis, subsets of patients with ALL who have a better or worse prognosis than average has contributed greatly to the success of modern treatment programs and to the definition of risk-benefit ratio. Initial serum LDH is increased in most patients with $\mathrm{ALL}^{2}$. A simple method of determination of prognosis was a demanding requirement. Therefore, this study was designed to identify the prognostic value of the initial LDH level in treatment of ALL.
1. * Dr. Muhammad Tawfique Consultant, Pediatrics and Pediatric Hematology \& Oncology, Square Hospitals Ltd, Dhaka.

2. Prof M A Mannan Professor of Pediatric Hematology \& Oncology

3. Prof. Dr. Mirza Manjurul Haque Professor, Pediatrics, Community Based Medical College, Bangladesh.

4. Dr. Mamtaz Begum Asst Professor, Hematology, National Institute of Cancer Research \& Hospital, Dhaka

5. Dr. Shah Md Rashed Zahangir Kabir Asst Professor, Pediatric Oncology, National Institute of Cancer Research \& Hospital, Dhaka

6. Dr. Zohora Jameela Khan Asst Professor, Pediatric Oncology, National Institute of Cancer Research \& Hospital, Dhaka

* Address of correspondence

Email : mtawfique@gmail.com Mobile : 01711388342 
The Objectives of the study was

1. The relationship of initial LDH levels with initial tumor load in childhood ALL.

2. The relationship of initial LDH levels to the response to induction chemotherapy in childhood ALL.

\section{Methods:}

This was a prospective, interventional study conducted at the department of Pediatric Hematology and Oncology, BSMMU, during the period of January 2004 to June 2005.

All the cases admitted into the department with the clinical suspicion of acute leukemia were investigated. They were enrolled into the study on the basis of the following criteria.

- Inclusion criteria:

The cases, which met the following criteria, were selected for the study. The criteria are described as in below.

i. Age: One year to 14 years.

ii. Sex: Male and female.

iii. After the confirmation of the diagnosis as ALL by bone marrow study.

- Exclusion criteria:

i. Previous history of taking steroid during this illness.

ii. Past history of chemotherapy.

iii. If the chemotherapy schedule was interrupted during the $1^{\text {st }} 7$ days of induction of remission.

iv. Parents disagreeing to be included in the study.

- Diagnosis of the cases:

Diagnosis of the cases was based on the history, clinical examination and laboratory investigations. The investigations were full blood count, peripheral blood film study, LDH level, x-ray chest, CSF analysis followed by the confirmation of the diagnosis by the study of bone marrow.

The diagnoses were established when at least $30 \%$ lymphoblasts were present in the bone marrow ${ }^{3}$. Bone marrow and peripheral blood film were stained by using Leishman staining technique. Bone marrow was also studied by cytochemistry reactions (Myeloperoxidase and Sudan Black B stains).
For the classification of ALL FrenchAmerican-British (FAB) criteria were used ${ }^{4}$.

- Assessment of tumor load:

Tumor load was assessed at diagnosis and before any anti-leukemic therapy was started. Assessment was done by the measurement of liver and spleen $(\mathrm{cm})$ from the costal margins of the respective sides, WBC and blast cell counts in peripheral blood film. When total WBC count was above $50 \times 10(9) / l$ the condition was labeled as hyperleukocytosis ${ }^{5}$. It was considered as high blast cell count as the blast cell was counted more than $25 \times 10(9) / l$.

\section{- Prechemotherapy:}

All the patients were given infusion fluid containing $5 \%$ dextrose in $0.225 \%$ or $0.45 \%$ $\mathrm{Nacl}$ iv $3 \mathrm{l} / \mathrm{m}^{2} /$ day, addition of sodibicarb (7.5\%) $25 \mathrm{ml}$ to each $500 \mathrm{ml}$ of baby saline, oral allopurinol $200 \mathrm{mg} / \mathrm{m}^{2} /$ day, triple intrathecal (By MTX, cytosar and hydrocortisone) and oral dexamethasone 2 $\mathrm{mg} / \mathrm{m}^{2}$ on day $1,4 \mathrm{mg} / \mathrm{m}^{2}$ on day 2 and 6 $\mathrm{mg} / \mathrm{m}^{2}$ on day 3 and onwards.

- Induction of remission:

During induction of remission chemotherapy was added to the treatment already been given in prechemotherapy phase. Induction chemotherapy was done (according to the chemotherapy protocol followed in the department of Pediatric Hematology and Oncology, BSMMU) by Vincristine iv 1.5 $\mathrm{mg} / \mathrm{m} 2$ weekly, intrathecal inj of MTX, Cytosar and Hydrocortisone, Daunorubicin 30 $\mathrm{mg} / \mathrm{m}^{2} /$ day in iv infusion on day 1 and day 2 as well as L-asparaginase $6000 \mathrm{u} / \mathrm{m}^{2} /$ day starting from day 3 of induction every alternate day for a total of 9 doses.

- Assessment of response to induction chemotherapy:

This was determined by bone marrow study every weekly till the complete remission was achieved. Bone marrow blasts less than $5 \%$ was considered as complete remission and that above $5 \%$ of total nucleated cells was labeled as bone marrow not in complete remission 6 . 
- Statistical analysis:

All the data were subjected to statistical analysis according to standard procedure. SPSS version 10.0 was used for statistical analysis. To identify the correlation between two groups of values Pearson's bivariate correlation test was performed. To compare the mean and SEM of two different groups of $A L L$, independent sample $t$ test or paired $t$ test was done accordingly. Pearson's chi square test was used to analyze the relationship of response of ALL to prechemotherapy dexamethasone with (i) initial WBC count, (ii) initial blast cell count and (iii) response to chemotherapy. The test (Pearson's chi-square test) was also done to analyze the relationship of initial WBC count and response to induction chemotherapy. $\mathrm{P}$ value less than 0.05 and $95 \%$ confidence interval (Cl) were used as the level of significance.

\section{Results:}

A total of 40 patients were enrolled in this study. Among them 21 were male and 19 female. As many as 24 patients were in the age group between 1 to 6 years, 10 between 7 to 10 years and the rest 6 above 10 years (Table 1).

Twenty-four out of forty cases $(60 \%)$ were from rural areas and 16 cases $(40 \%)$ were urban (Table 1).

Table 1 also showed the nutritional status by weight for age $Z$ score. It was observed that 4 $(10 \%)$ patients had moderate and 4 others had severe nutritional deficiency, 12 (30\%) had mild nutritional deficiency and the rest $20(50 \%)$ did not have any nutritional deficiency.

According to morphological classification 30 out of 40 cases $(75 \%)$ were of FAB L1 type and only $10(25 \%)$ were of FAB L2 variety. None of the cases enrolled was L3 (Table 1).

Table 1 presented the clinical features of the cases too. Here, 38 of 40 cases $(95 \%)$ were febrile, $18(45 \%)$ had bleeding, $6(15 \%)$ were mildly, $20(50 \%)$ moderately and 14 (35\%) were severely anemic. Lymphadenopathy was present in $30(75 \%)$ patients, $18(45 \%)$ presented with generalized and $12(30 \%)$ with localized lymphadenopathy. Hepatomegaly was found in all the cases but splenomegaly was found in $34(85 \%)$ of them. Bony tenderness was present in $12(30 \%)$ cases. Only $2(5 \%)$ had arthropathy. Genitourinary system was involved in 2 and respiratory system involvement in 2 others.

In Table 2, levels of initial LDH were correlated with initial WBC count. Although initial LDH was recorded in 34 cases, but initial WBC count was recorded at diagnosis, in all the 40 cases. Mean initial LDH level was $1026.59 \mathrm{u} / \mathrm{l}$ and SD was 846.49u/l. Calculated mean WBC count and SD were $36.55 \times 10^{9} / 1$ and $37.63 \times 10^{9} / /$ respectively. Initial WBC count had positive correlation with initial LDH levels $(C C=0.83 ; P=0.000)$ (Table 2).

Positive correlation $(C C=0.72 ; \mathrm{P}=0.000$ ) with initial LDH was also evident in case of IBC (initial blast count) where its mean value was $23.59 \times 10^{9} /$. SD was $30.55 \times 10^{9} / 1$ (Table 2).

As correlation of initial hepatomegaly and initial LDH level was studied, mean hepatomegaly was observed $5.7 \mathrm{~cm}$ (SD = $1.28 \mathrm{~cm})$. No statistical correlation could be detected with initial LDH levels $(C C=0.287$; $P=0.099$ ) (Table 2). Similarly, no correlation of size of spleen with initial LDH levels was observed as Table 2 presented the observations with mean splenomegaly was $3.85 \mathrm{~cm}$ with the SD being $3.4 \mathrm{~cm}$. Correlation coefficient was $0.53(P=0.291)$ in this case.

Table 3 compared the difference of initial LDH levels between hyperleukocytosis $(\geq 50 \mathrm{x}$ $\left.10^{9} / \mathrm{l}\right)$ and high $\left(<50 \times 10^{9} / \mathrm{l}\right)$ WBC groups of ALL. As 10 cases were documented to have the count $50 \times 10^{9} / /$ or more, their mean initial LDH level was $2026.80 \mathrm{u} / \mathrm{l}$ (SEM $=284.52$ $\mathrm{u} / \mathrm{l})$. On the other hand, 24 cases had initial WBC count less than $50 \times 10^{9} / /$ with their mean initial LDH value as low as $609.83 \mathrm{u} / \mathrm{l}$ $(\mathrm{SEM}=62.96 \mathrm{u} / \mathrm{l})$. The difference was highly significant statistically $(\mathrm{t}=4.86, \mathrm{df}=9.89, \mathrm{P}=$ $0.001 ; 95 \% \mathrm{Cl} 766.73$ to 2067.20 ).

Table VI have the comparison of initial LDH levels between the cases of ALL having IBC (Initial blast count) above and below the levels of $25 \times 0^{9} / l$. Twelve patients were observed to have IBC more than $25 \times 10^{9} / \mathrm{I}$ 
with the mean initial LDH level of $1725.50 \mathrm{u} / \mathrm{l}$ $(\mathrm{SEM}=310.18 \mathrm{u} / \mathrm{l})$. Twenty-two patients presenting with IBC less than $25 \times 10^{9} / \mathrm{l}$, had their mean LDH level of $645.36 \mathrm{u} / \mathrm{l}$ (SEM = $63.92 \mathrm{u} / \mathrm{l})$ (Fig.11). The difference was proved statistically significant $(\mathrm{t}=3.41, \mathrm{df}=11.94, \mathrm{P}=$ $0.005 ; 95 \% \mathrm{Cl} 389.75$ to 1770.52 ).

In Table VII, initial LDH levels were compared between the early and late bone marrow response groups. Six patients with relatively higher initial LDH levels (Mean $=1973.67$, SEM = $440.99 \mathrm{u} / \mathrm{l}$ ) went into remission beyond 7 days after induction but the other 28 patients having comparatively lower initial LDH $($ Mean $=823.64$, SEM $=122.13)$ went into remission within 7 days of instituting induction of remission. The difference was proved statistically significant $(P=0.001$; $95 \% \mathrm{Cl} 479.94$ to 1820.10 ).
Table 1: Characteristics of the cases:

\begin{tabular}{|c|c|c|c|c|c|}
\hline & & 1 to $6 y r s$ & 7 to $10 \mathrm{yrs}$ & $>10$ yrs & Tota \\
\hline ख & Male & 15 & 4 & 2 & 21 \\
\hline & Female & 9 & 6 & 4 & 19 \\
\hline $\begin{array}{l}\text { ष } \\
\end{array}$ & Rural & & & & 24 \\
\hline$\frac{0}{8}$ & Urban & & & & 16 \\
\hline $\bar{\sigma}$ & Normal & & & & 20 \\
\hline : & Mild & & & & 12 \\
\hline 焉 蛋 & Moderate & & & & 4 \\
\hline & Severe & & & & 4 \\
\hline 을 & L1 & & & & 10 \\
\hline$\stackrel{8}{\mathscr{E}}$ & L2 & & & & 30 \\
\hline
\end{tabular}

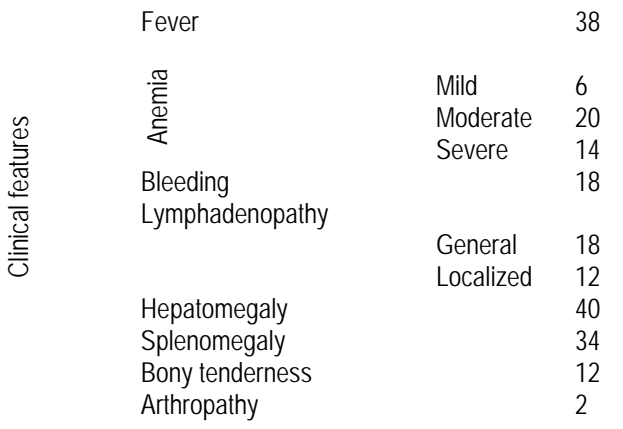

Table 2: Correlations of initial LDH level with initial WBC count, initial blast cell count (IBC), size of the liver and spleen

\begin{tabular}{|lrcrr|}
\hline & Number of the cases & Mean $( \pm \mathrm{SD})$ & Correlation Coefficient & $\mathrm{P}$ \\
LDH & 34 & $1026.59( \pm 846.49) \mathrm{u} / \mathrm{l}$ & 1 & 0.00 \\
WBC & 40 & $36.55( \pm 37.63) \times 10^{9} / 1$ & $0.83^{*}$ & 0.00 \\
IBC & 40 & $23.59( \pm 30.55) \times 10^{9} / 1$ & $0.72^{*}$ & 0.00 \\
Liver & 40 & $5.7( \pm 1.28) \mathrm{cm}$ & $0.28^{*}$ & 0.09 \\
Spleen & 40 & $3.85( \pm 3.40) \mathrm{cm}$ & $0.53^{*}$ & 0.29 \\
\hline
\end{tabular}

*Values compared with that of LDH

Table 3: Comparison of mean (SEM) initial LDH levels between the groups of ALL with initial hyperleukocytosis $\left(\geq 50 \times 10^{9} / \mathrm{l}\right)$ and high $\left(<50 \times 10^{9} / \mathrm{l}\right) \mathrm{WBC}$ count

\begin{tabular}{|lccc|}
\hline WBC & No of patients $(n=34)$ & Mean & LDH u/l \\
& & SEM \\
$\geq 50 \times 10^{9} / l$ & 10 & 2026.80 & 284.52 \\
$<5010^{9} / l$ & 24 & 609.83 & 62.96 \\
\hline
\end{tabular}

$\mathrm{t}=4.86, \mathrm{df}=9.89, \mathrm{P}=0.001$ (95\% Cl 766.73 to 2067.20$)$ 
Original Article

Table 4: comparison of mean (SEM) initial LDH levels between the cases containing high $\left(\geq 25 \times 10^{9} /\right.$ l) and lower $\left(<25 \times 10^{9} / /\right)$ peripheral blast count

\begin{tabular}{|l|c|c|}
\hline \multirow{2}{*}{ Initial blast cell count } & \multicolumn{2}{|c|}{ LDH u/l } \\
\cline { 2 - 3 } & Mean & SEM \\
\hline$\geq 25 \times 10^{9} / /$ & 1725.50 & 310.18 \\
\hline$<25 \times 10^{9} / I$ & 645.36 & 63.92 \\
\hline
\end{tabular}

$\mathrm{t}=3.4111, \mathrm{df}=11.943, \mathrm{P}=0.005(95 \% \mathrm{Cl} 389.75$ to 1770.52$)$

Table 5: Comparison of mean (SEM) initial LDH levels between groups of ALL going into remission by day 7 and after day 7 of induction chemotherapy

\begin{tabular}{|l|c|c|}
\hline \multirow{2}{*}{ Bone marrow remission $(\mathrm{n}=34)$} & \multicolumn{2}{|c|}{ LDH $\mathrm{u} / \mathrm{l}$} \\
\cline { 2 - 3 } & Mean & SEM \\
\hline After day 7 of induction $(\mathrm{n}=6)$ & 1973.67 & 440.99 \\
\hline By day 7 of induction $(\mathrm{n}=28)$ & 823.64 & 122.13 \\
\hline
\end{tabular}

$\mathrm{T}=3.49, \mathrm{df}=2, \mathrm{P}=0.001(95 \% \mathrm{Cl} 479.94$ to 1820.10$)$

\section{Discussion}

Lactate dehydrogenase, a pyridine-linked enzyme found in virtually all animal tissues, functions primarily in the metabolism of glucose, catalyzing the reduction of free pyruvate to lactate during the last step of glycolysis, as well as conversion of lactate to pyruvate during gluconeogenesis. Its concentration is highest in liver following in descending order by skeletal muscle, heart and kidney. Malignant cells have distinctive type of metabolism in which the glycolytic sequence and the tricarboxylic acid cycle are poorly integrated; hence, the cells tend to utilize from five to ten times as much glucose as do normal tissues, converting most of it into lactate ${ }^{7}$.

In this study, mean initial LDH level was very high suggesting high tumor load in all the cases. Initial LDH levels had strong positive correlation with initial WBC count $(C C=0.83$; $P=0.000$ ). The finding is consistent with that of the other workers ${ }^{8}$. They showed higher LDH was associated with higher WBC count at diagnosis. This view was also supported by the findings obtained here as this study showed that when WBC count was at or more than $50 \times 10^{9} / /$ mean LDH level was very significantly higher than its mean level when the count was less than $50 \times 10^{9} / /(P=0.001$; $95 \% \mathrm{Cl} 766.73$ to 2067.20 ).

The present study showed that initial blast cell count also had strong positive correlation with initial LDH levels $(C C=0.72 ; P=0.000)$. The more was the initial blast cell count the higher was initial LDH level. This positive correlation is conceivable here, as initial LDH gets high with high WBC count and quite understandably high initial blast cell count contributed to high initial WBC count. So, as the tumor load increased initial LDH also mounted up. This finding was further strengthened by the comparison of the mean initial LDH levels between the two groups of ALL- one containing higher $(\geq 25 \times 10(9) / /$ ) initial blast count and the other with that of the lower $(<25 \times 10(9) / l)$ initial count. The mean level of initial LDH was found significantly more in the former than the level of the later group of ALL ( $P=0.005 ; 95 \% \mathrm{Cl} 389.75$ to 1770.52).

But initial LDH levels did not have any correlation with the size of the liver $(\mathrm{CC}=$ $0.28 ; P=0.09)$ and spleen $(C C=0.53 ; P=$ 0.29 ) in this study. The finding was not consistent with that of Pui et $\mathrm{al}^{8}$.

Another comparison of mean initial LDH level between the groups going into very early (Remission within 7 days of induction chemotherapy) into remission and the group requiring more than 7 days of induction chemotherapy to go into remission, were shown. Here also, the former group had lower initial LDH level of statistical significance than that in the later $(P=0.001 ; 95 \% \mathrm{Cl} 479.94$ to 1820.10). The finding here was another 
supportive evidence in favor of using initial $\mathrm{LDH}$ level as a prognostic factor in the treatment of childhood ALL. A report from the Children's Cancer Study Group (CCSG) by Miller and Coccia $^{9}$ could show that clearance of blast cells from the bone marrow in the early part of induction of remission was a favorable prognostic indicator for the children with ALL. They showed that this early response to induction therapy was a predictor of disease free survival and late recurrence of childhood ALL. Although our study could not be stretched to the end of full chemotherapy course yet outcome of induction chemotherapy could be clearly evident here. Lower initial LDH level was found to be an indicator of better outcome following induction chemotherapy highlighting the importance of initial LDH in risk assessment as well as risk based stratification of childhood ALL even before the treatment of induction chemotherapy begins. Therefore, this initial $\mathrm{LDH}$ level can also help pediatric oncologists in risk based stratification of childhood ALL cases. Thereby, this initial LDH level can be of significant help for a pediatric oncologist in developing countries where immunophenotyping is neither easily available nor affordable to most of the population, to take the decision whether to start induction chemotherapy with three drug induction protocol or to start with more intensive ones with four or five drugs.

This was a study done in a very limited period of time. Immunophenotype and cytogenetics could not be done because of the unavailability of the procedures at that time in BSMMU. Could we do immunophenotype and cytogenetics for the sub-classification of our cases, if we could have the opportunity to stretch the study time and follow these patients up through their whole maintenance to the end of therapy the outcome would be much more gratifying.

\section{Conclusion:}

Level of initial LDH was observed to be a significant indicator of outcome of induction of remission in childhood Acute Lymphoblastic Leukemia. Initial LDH level could be considered as an important tool for risk based assessment of classification before the start of chemotherapy in the phase of induction of remission particularly in the areas where immunophenotyping is not easily available nor is it affordable to most of the population of the region.

\section{References}

1. Dordelmann $M$, Reiter A, Borkhardt A, Ludwig W-D, Gutz N, Viehmann S, Gadner H, Riehm $H$, Schrappe M. Prednisolone response is the strongest predictor of treatment outcome in infant acute lymphoblastic leukemia. Blood 1999; 94: 1209-1217.

2. Hafiz MG, Mannan MA. Serum Lactate Dehydrogenase levels in childhood Acute Lymphoblastic Leukemia. Bangladesh Med Res Council Bull 2007 Dec; 33 (3):88-91.

3. Bain BJ. Acute Leukaemia Cytology, Cytochemistry, and the FAB classification. Leukemia Diagnosis. $2^{\text {nd }}$ ed. Oxford; Blackwell Science Ltd1999; 1-52.

4. Bennett JM, Catovsky, Daniel MT. French American-British (FAB) Co-opreative group: the morphological classification of acute leukemias-concordance among observers and clinical correlation. Br J Hematol 1981; 47: 553561.

5. Kanerva J. Prognostic factors in childhood and acute lymphoblastic leukemia (Dissertation) 2001; Finland, University of Helsinki.

6. Steinherz PG, Faynon PS, Breneman JC, Cherlow JM, Grossman NJ, Kersey JH, Jhonstone HS, Sather HN, Trigg ME, Chappell $R$, Hammond D, Bleyer WA. Cytoreduction and prognosis in acute lymphoblastic leukemia the importance of early marrow response: report from the children's cancer group. J Clin Oncol 1996; 14: 389-398.

7. Chung $F Z$, Tsujibo $H$, Bhattacharyya $U$, Sharief FS, LI SS. Genomic organization of human lactate dehydrogenase A gene. Biochem. J. 1985; 231 (3): 537-41.

8. Pui CH, Dodge RK, Dahl GV, Rivera G, Look AT, Kalwisky D, Bowman WP, Ochs J, Abromowitch M, Mirro J. Serum Lactic dehydrogenase has prognostic value in childhood acute lymphoblastic leukemia. Blood 1985; 66: 778-82

9. Miller DR, Coccia PF, Bleyer WA, Leukens JN, Siegel SE, Sather HN, Hammond GD. Early response to induction therapy as a predictor of disease free survival and the recurrence of childhood acute lymphoblastic leukemia: a report from the children's cancer study group. J Clin Oncol 1989; 7: 1807-1815. 